Int. J. of The Soc. of Mat. Eng. for Resources Vol. 3 No. 1 142 149 (1995)

\title{
Original
}

\section{Influence of Particle Shape on Ball Mill Grindability}

\author{
by \\ Yoshiteru KANDA $^{\dagger}$ and Etuko KImURA ${ }^{\dagger}$
}

\begin{abstract}
Ball mill tests on laboratory scale were carried out in order to study the influence of particle shape on grindability. The sample used was $1362 \mathrm{~g}, 10,000$ pieces of $4 \times 6$ mesh limestone. The shape index defined by (diameter of a circumcircle/thickness) was measured manually with great care by slide caliper and the particles were classified into two groups on the basis of the shape index. The grinding mill used was made of stainless steel and its volume was about 2.7 liters. The grinding medium charged also consisted of 144 stainless steel balls of diameter $1.9 \mathrm{~cm}$. The mill was always run at a rotational speed of $112 \mathrm{rev}$. $/$ min. It was found that the shape index of feed material affects the decreasing rate of mass fraction of feed size and the increasing rate of fine particles.
\end{abstract}

Key Words : Ball Mill, Grindability, Limestone, Shape Index

\section{INTRODUCTION}

The powdered and granular materials which are processed in industries range widely in particle size. Particle shape of these materials is not uniform ${ }^{1)}$. The importance of particle shape in determining single particle or bulk powder properties is now recognized in a great variety of industries. The influence of particle shape on the properties of bulk material have not been extensively documented, although it is well known that differences in particle shapes influence the behavior of material during processing and handling. It has been reported that the particle shape affects the sieving rate ${ }^{2 \sim 4)}$, the flow behavior ${ }^{5 \sim 8)}$, the static and dynamic properties of powder bed ${ }^{9,10)}$, the measurement of size distribution $^{11 \sim 13)}$, agglomeration ${ }^{14)}$ and other ${ }^{15)}$. A number of papers have already been published on the subject of the shape of comminuted particles ${ }^{1620)}$. However there were few papers ${ }^{21)}$ devoted to the influence of particle shape on grindability. Subsequently, the relationships between the particle shape and the grindability or the probability of fracture in a previous paper ${ }^{22)}$ was studied. In this paper, the influence of patricle shape of feed material on grindability is investigated by grinding differently shaped particles of limestone in a laboratoru-scale ball mill.

\footnotetext{
Received February 6, 1995

$\dagger$ Department of Materials Science and Engineering, Yamagata University, 4-3-16, Jonan, Yonezawa, 992, Japan
} 


\section{MATERIAL}

The sample selected was limestone and its properties are tabulated in Table 1. In order to obtain

Table 1. Propeties of limestone.

\begin{tabular}{|c|c|c|c|c|c|c|}
\hline Density & $\begin{array}{l}\text { Young } \\
\text { modulus }\end{array}$ & $\begin{array}{c}\text { Poisson } \\
\text { ratio }\end{array}$ & $\begin{array}{l}\text { Work } \\
\text { index }\end{array}$ & $\begin{array}{c}\text { Hardgrove } \\
\text { grindability } \\
\text { index }\end{array}$ & $\begin{array}{l}\text { Vicker's } \\
\text { hardness }\end{array}$ & $\begin{array}{c}\text { Mohs } \\
\text { hadness }\end{array}$ \\
\hline$\left[\mathrm{kg} / \mathrm{m}^{3}\right]$ & {$[\mathrm{Pa}]$} & {$[-]$} & {$[\mathrm{kwh} / \mathrm{t}]$} & {$[-]$} & {$\left[\mathrm{kg} / \mathrm{mm}^{2}\right]$} & {$[-]$} \\
\hline $2.7 \times 10^{3}$ & $6.8 \times 10^{10}$ & 0.32 & 9.4 & 73 & 115 & 4 \\
\hline
\end{tabular}

a sample ranging from 4 mesh $(0.476 \mathrm{~cm})$ to 6 mesh $(0.336 \mathrm{~cm})$, a massive limestone was crushed in a jaw crusher. About $200 \mathrm{~g}$ of crushed product was classified by sieving for $10 \mathrm{~min}$, using a rotating and tapping shaker to obtain about $20 \mathrm{~g}$ of sample. The number of specimens prepared were 10,000 pieces of $1362 \mathrm{~g}$.

\section{MEASUREMENT OF SHAPE INDEX}

Two kinds of shape factors evaluating the particle shape has been widely used in powder technology. One is shape coefficient and other is shape index. The former is determined as the coefficient which characterizes the effect of particle shape in the equations describing the physical properties or behaviours of powders. The latter, on the other hand, expresses the shape itself morphologically and mathematically. Sphericity and elongation are examples.

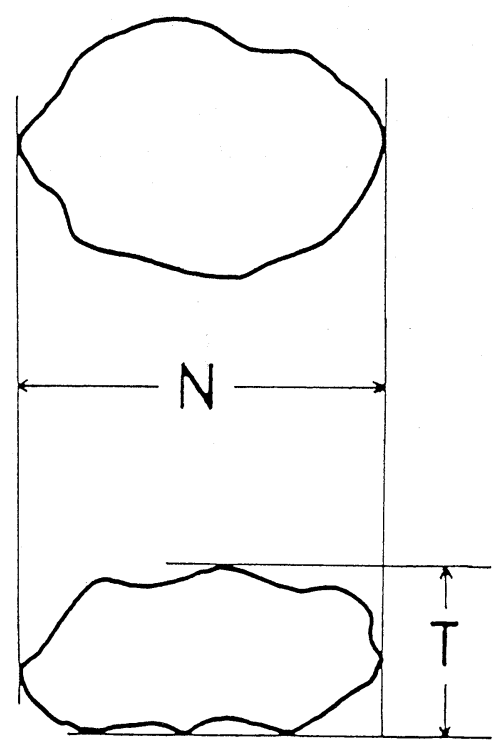

Fig 1: Definition of diameter of a circumcircle and thickness 


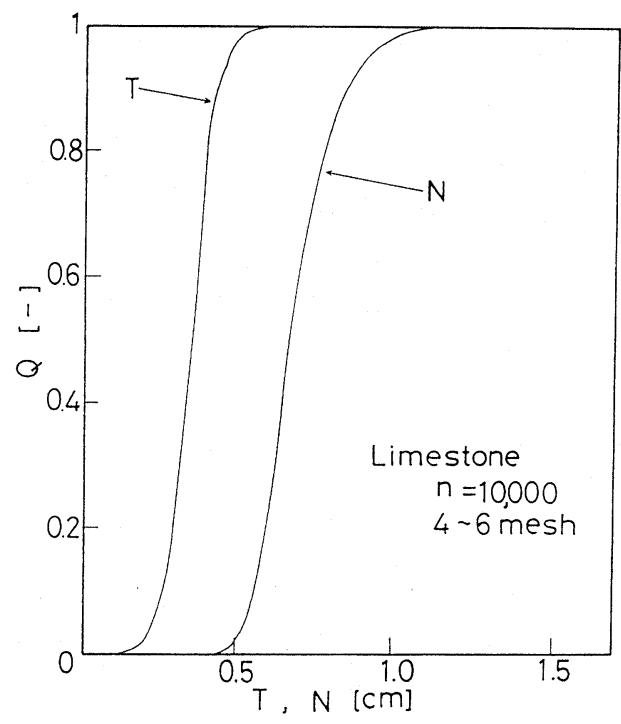

Fig 2 : Cumulative distributions of thickness and diameter of a circumcircle for $4 \times 6$ mesh limestone.

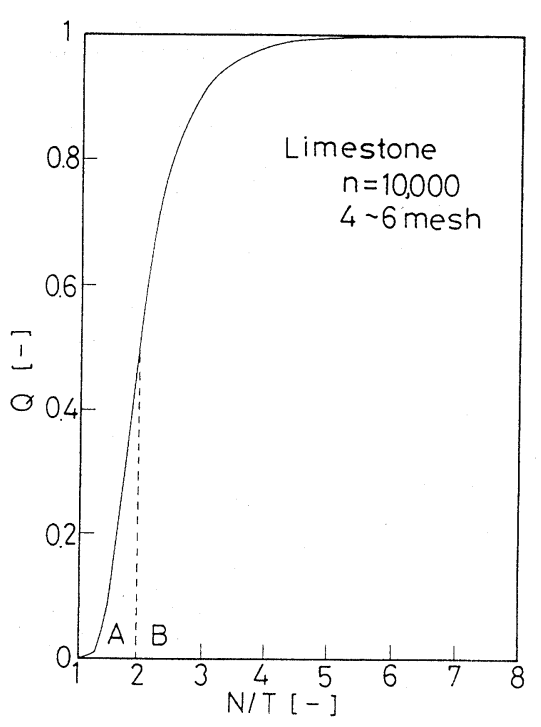

Fig 3 : Cumulative shape index distribution for $4 \times 6$ mesh limestone.

In order to examined the influence of particle shape on grindability, we had measured eight kinds of particle sizes and calculated seven kinds of shape indices on sieved particles. A crushing test had been performed using a simple drop weight method to evaluate the influence of the shape indices on grindability of feed particles. It had been found that the shape indices defined by (diameter of a circumcircle/thickness), (length/thickness) and (Feret's diameter/thickness) were useful to characterize the grindability of differently shaped particles ${ }^{23)}$.

In this paper, we measured the shape index, (diameter of a circumcircle/thickness), of 10,000 pieces prepared by slide caliper. The definition of these is showm Fig. 1. The cumulative distributions of thickness $\mathrm{T}$, diameter of a circumcircle $\mathrm{N}$ and the shape index $\mathrm{N} / \mathrm{T}$ are shown in Figs. 2 or 3. The arithmetic mean and coefficient of variation of $\mathrm{T}, \mathrm{N}$ and $\mathrm{N} / \mathrm{T}$ are also tabulated in Table 2 . The 10,000 pieces were classified into two groups, $\mathrm{A}$ and $\mathrm{B}$, on the basis of the shape index to be at the same mass, 681g, as shown Figs. 3 and 7. Number of specimens, mass, mean shape indices, range of shape index and coefficient of variation of shape index in each group are tabulated in Table 3 respectively.

Table 2. Mean particle sizes and shape indices of specimens prepared.

\begin{tabular}{c|c|c}
\hline & Mean & $\begin{array}{c}\text { Coefficient of } \\
\text { variation } \\
{[-]}\end{array}$ \\
\hline $\mathrm{T}$ & $0.344[\mathrm{~cm}]$ & 0.205 \\
$\mathrm{~N}$ & $0.691[\mathrm{~cm}]$ & 0.177 \\
$\mathrm{~N} / \mathrm{T}$ & $2.10[-]$ & 0.309 \\
\hline
\end{tabular}


Table 3. Number, mass, mean shape indices and range of shape index of specimens prepared.

\begin{tabular}{c|c|c|c|c|c}
\hline Group & $\begin{array}{c}\text { Number of } \\
\text { specimens } \\
{[-]}\end{array}$ & Mass & $\begin{array}{c}\text { Mean shape } \\
\text { index } \\
{[-]}\end{array}$ & $\begin{array}{c}\text { Range of } \\
\text { shape index } \\
{[-]}\end{array}$ & $\begin{array}{c}\text { Coefficient } \\
\text { of variation } \\
{[-]}\end{array}$ \\
\hline $\mathrm{A}$ & 4922 & 681 & 1.65 & $1.07 \sim 1.94$ & 0.110 \\
$\mathrm{~B}$ & 5078 & 681 & 2.54 & $1.95 \sim 7.13$ & 0.246 \\
\hline
\end{tabular}

\section{EXPERIMENTAL APPARATUS AND METHOD OF GRINDING}

The grinding mill used was made of stainless steel and had a diameter of $15.2 \mathrm{~cm}$ and inner length of $15.2 \mathrm{~cm}$. Its volume was about 2.7 liters. The grinding medium charged consisted of $4.14 \mathrm{~kg}$ of 144 stainless steel balls of diameter $1.9 \mathrm{~cm}$ and density $7.94 \times 10^{3} \mathrm{~kg} / \mathrm{m}^{3}$. The ball load is same as the one which was determined by preparatory experiments for coal grinding as reported in a previous paper $^{24)}$.

The mill speed was kept constant at 112 r.p.m. which corresponds to $97 \%$ of the critical speed. The sample, A and B, were ground separately. One half of the ground product was sieved in a rotating and tapping shaker. The sieves used were $6,100,200$, mesh and the diameter of these was $21 \mathrm{~cm}$. The mass of sample charged to the top sieve was about $113 \mathrm{~g}$ and sieving time was $10 \mathrm{~min}$.

\section{RESULTS AND DISCUSSION}

The variations of the mass fraction of feed size $(4 \times 6$ mesh $)$ with the grinding time, that is, firstorder for two samples are shown in Fig. 4. This figure shows that the specific grinding rate of sample $B$ is higher than A which has lower value of mean shape index $N / T$. The data plotted in the figure

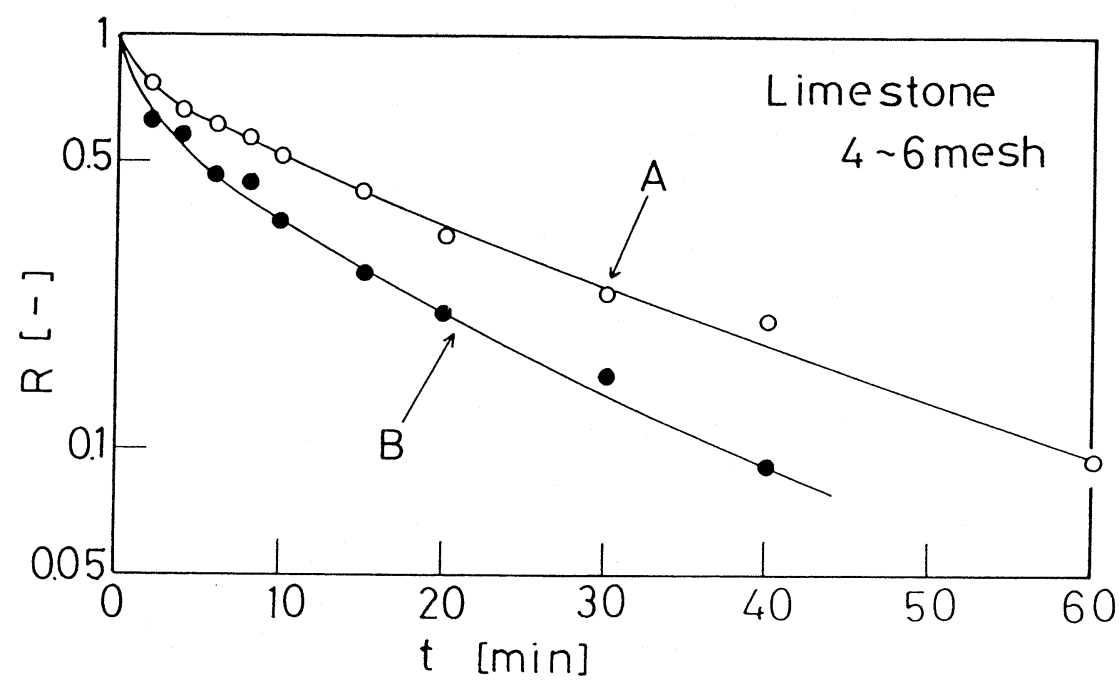

Fig 4 : First - order plots of $4 \times 6$ mesh limestone. 


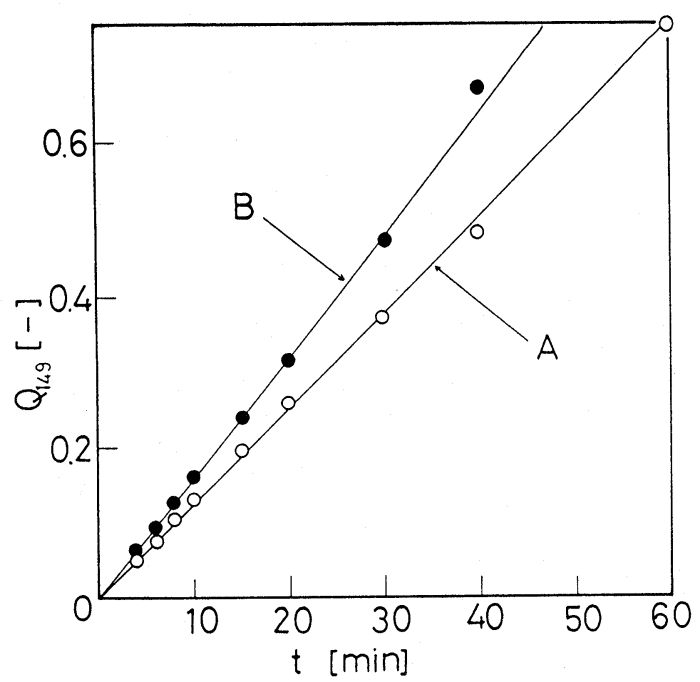

Fig 5 : Variation of mass fraciton finer than 100 mesh $(149 \mu \mathrm{m})$ with grinding time.

does not exhibit first-order grinding kinetics behaviour. The reason for this is that when a feed size in large, the weaker particle breakes more readily and is removed due to the combined effect of a distribution of applied forced in a mill and a distribution of strength of particles as proposed by Austin et $\mathrm{al}^{25)}$. Thus, the mean strength of particles of a given size remaining in a mill becomes greater as grinding time increases. The variations of the mass fraction finer than 100 mesh $(149 \mu \mathrm{m}) \mathrm{Q}_{149}$ with grinding time are shown in Fig. 5. Figure 5 shows that the difference in the particle shape of feed material affects the increasing rate of fine particles too.

In order to evaluate the influence of particle shape on the grindability with changing the cut size, the variations of the ratio of mass of ground product for sample $B, Q_{B}$, to sample $A, Q_{A}$, with the

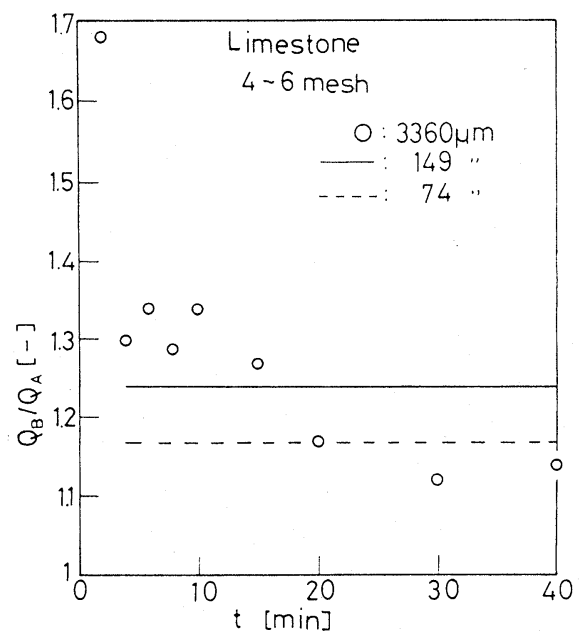

Fig 6: Variation of $\mathrm{Q}_{\mathrm{B}} / \mathrm{Q}_{\mathrm{A}}$ with grinding time. 


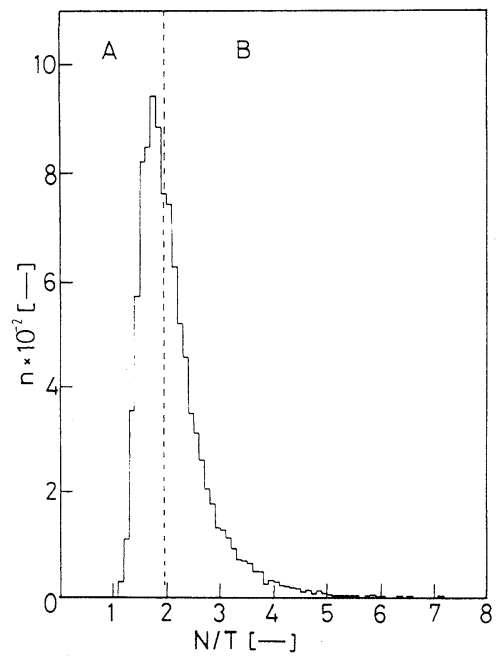

Fig 7 : Density distribution of shape index for $4 \sim 6$ mesh limestone.

grinding time are shown in Fig. 6 as a function of the cut size. In general, an increasing rate of fine grinding follows the zero-order kinetic law at first ${ }^{26,27)}$ expressed by eq. (1).

$$
Q=\mathbf{k}_{0} \mathbf{t}
$$

Then, in the case that the cut size are 149 and $74 \mu \mathrm{m}$, the ratio of rate constant expressed by Eq. (1) are used instead of $\mathrm{Q}_{\mathrm{B}} / \mathrm{Q}_{\mathrm{A}}$ as the parameter in Fig. 6. The difference of shape index affects considerably the decreasing rate of mass fraction of feed size in early stage. The shape index of feed particles affects also in fine grinding but the influence decreases with decrease in the cut size.

In this study, we had to classify the limestone particles by the value of shape index having a high density as shown in Fig. 7 to get two samples which have different mean shape indices with same mass

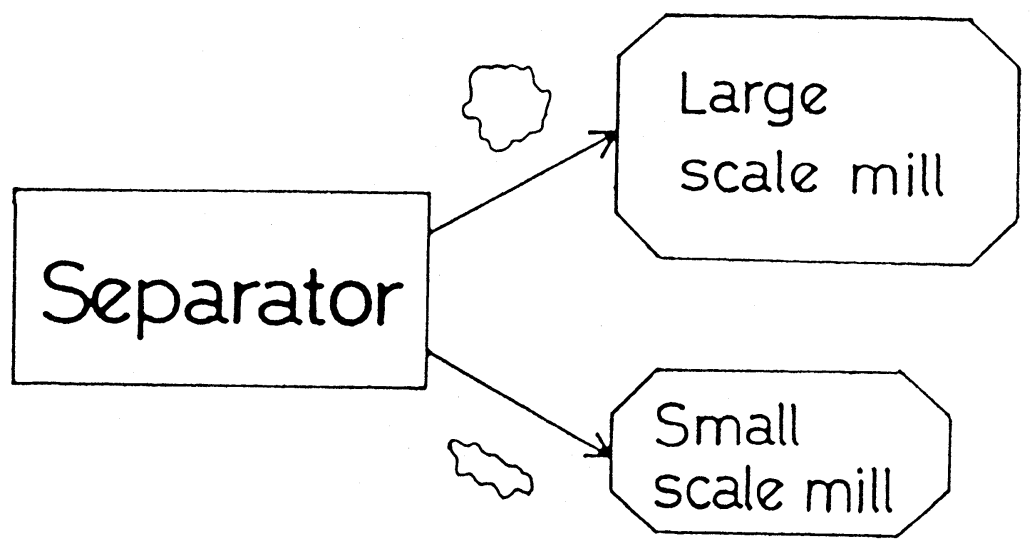

Fig 8 : Schematic diagram of grinding process proposed. 
respectively. Subsequently, we could't obtain the experimental results which explained sufficiently the influence of shape index on a ball mill grindability. There are many methods ${ }^{28}$ to separate the differently shaped particles. If it is possible to separate the particles at the desired shape index, a schematic diagram as shonwn in Fig. 8 will be applicable to a new grinding process in order to reduce the overgrinding.

\section{CONCLUSION}

In general, the powdered or granular materials consist of differently shaped particles. In this paper, laboratory-scale ball mill tests were carried out for the purpose of quantitative investigation of the influence of particle shape on the grindability. The results are summarized as follow :

(1) The ball mill grindability of limestone increased with increase in shape index.

(2) The considerable influence of shape index on grindability was observed in decreasing rate of mass fraction of feed size at early stage but it decreased rapidly with increase in the grinding time.

(3) The influence was also observed in increasing rate of fine particles. But it decreased with de crease in particle size produced.

(4) It was proposed that a new grinding process which include a separator of differently shaped particles.

\section{LIST OF SYMBOLS}

$\mathbf{k}_{0}$ : zero-order increasing rate constant $\left[\mathrm{min}^{-1}\right]$

$\mathrm{n}:$ number of specimens $[-]$

$\mathrm{N}$ : diameter of a circumcircle $[\mathrm{cm}]$

$\mathbf{N} / \mathbf{T}$ : shape index $[-]$

$\mathrm{Q}$ : cumulative fraction of under size or shape index [-]

$\mathbf{Q}_{\mathrm{A}}$ : mass fraction of under size for sample $A[-]$

$Q_{B}$ : mass fraction of under size for sample $B$ [-]

$\mathrm{Q}_{149}:$ mass fraction finer than $149 \mu \mathrm{m}$ [-]

$\mathrm{R}:$ mass fraction of feed size [-]

$\mathrm{T}:$ thickness $[\mathrm{cm}]$

$\mathrm{t}$ : grinding time $[\mathrm{min}]$

\section{REFERENCES}

1) J. Tsubaki and G. Jimbo : Powder Technol. , 22, 171 (1979)

2) J. W. Novak and J. R. Thompson : ibid, 45, 159 (1989)

3) T. Shibata, S. Nakayama and K. Yamaguchi : J. Soc. Powder Technol., Japan, 25, 615 (1988)

4) N. N. Clark and T. P. Meloy : Powder Technol., 54, 271 (1988)

5) H. G. Constable, ibid., 20, 177 (1978)

6) A. Guo, J. K. Beddow and A. F. Vetter : ibid, 43, 279 (1985)

7) M. J. Yin, J. K. Beddow and A. f. Vetter : ibid, 46, 53 (1986)

8) T. Tsuji and K. Yamaguchi : J. Soc. powder Technol., Japan, 24, 509 (1987)

9) I. Nikolakakis and N. Pilple : Powder Technol., 46, 53 (1986) 
10) M. Hirota, T. Ishihara, A. Sugai and T. Oshima : J. Soc. powder Technol., Japan, 23, 66 (1986)

11) M. Arakawa, T. Yokoyama, T. Yamaguchi and T. Minami : J. Soc. Material Science, Japan, 32, 966 (1983)

12) Y. Kousaka : J. Soc. Powder Technol., Japan, 26, 433 (1989)

13) Y. Kanda and Y. Abe : ibid, 27, 404 (1990)

14) M. Ozaki, T. Egami, N. Sugiyama and E. Matijevic : J. Colloid Interface Sci., 126, 219 (1988)

15) T. P. Meloy : Powder Technol., 16, 233 (1977)

16) E. H. Yoffe : Phil. Magazine, 42, 739 (1951)

17) R. J. Charles : Trans. A. I. M. E., 1028 (1956)

18) S. Okuda and Y. Morita : J. Soc. Powder Technol. , Japan, 4, 800 (1967)

19) C. B. Holt : Powder Technol., 28, 59 (1981)

20) Y. Kuga, Ma. Xinghua, J. Koga, S. Endoh and I. Inoue : J. Chem. Eng, Japan, 44, 281 (1985)

21) T. Honma, M. Hasegawa and Y. Kanda : ibid, 17, 221 (1984)

22) Y. Kanda, Y. Makuta and T. Imamura : J. Min. Materials processing, Inst., Japan, 105, 995 (1989)

23) Y. Kanda, T. Yamashita, H. Sasaki and S. Niiyama : J. Soc. Powder Technol., Japan, 24, 635 (1987)

24) Y. Kanda, H. Murata and T. Honma : Powder Technol., 58, 175 (1989)

25) L. G. Austin and K. Shoji : ibid, 7, 3, (1973)

26) N. Arbiter and U. N. Bhrany : Trans. A. I. M. E., 217, 245 (1960)

27) Y. Kanda and T. Abe : J. Soc. Material Science, Japan, 27, 980 (1978)

28) S. Sano : J. Soc. Materials Engineering for Resources, Japan, 3, 128 (1990) 